\title{
PERSONA Y CONCIENCIA EN SANTO TOMÁS DE AQUINO
}

\author{
Eudaldo Forment \\ Universidad de Barcelona
}

\begin{abstract}
RESUMEN
El constitutivo fundamental de la persona, para Santo Tomás, es el ser. El ser personal es el ser del espíritu. La persona, por ello, expresa lo más individual o incomunicable. La conciencia moral es propia de la persona. El proceso discursivo de la conciencia requiere la individualidad personal. No obstante, en la conciencia personalista no se funda una ética individualista ni subjetivista.
\end{abstract}

Palabras clave: Santo Tomás, persona, conciencia, incomunicabilidad, ley

\begin{abstract}
The fundamental constituent of the person, according to Saint Thomas, is the being. The personal is the being of the spirit. Therefore, the person expresses the most individual or isolated thing. The moral sense is characteristic of the person. The discursive process of the moral sense assumes the personal individuality. Nevertheless, the personalist moral sense of the Aquinist establishes neither an individualist nor a subjectivist ethics.
\end{abstract}

Key words: Saint Thomas, person, moral sense, incommunicability, law.

Joaquín Lomba, fundador y director de la Revista Española de Filosofia Medieval y Presidente, desde 1989, de la Sociedad de Filosofía Medieval, es conocido en todo el mundo por su paciente y constante labor investigadora de la cultura hispano-semita, que se ha traducido en valiosas publicaciones. También es muy renombrada, especialmente entre los que tenemos la suerte de contarnos entre sus numerosos amigos, su gran bondad, que se manifiesta en su afabilidad, benevolencia, respeto hacia los demás, su carácter armonizador y conciliador, y su gran modestia. Siempre he creído que estas y otras de sus cualidades son los propios de una gran persona y de su rectitud moral.

Para exprersarle mi admiración, y también mi afecto y gratitud, quiero ofrecerle las siguientes reflexiones sobre la doctrina de la persona y de la conciencia de Santo Tomás de Aquino. Considero que pueden servir de homenaje al profesor Lomba, un gran universitario aragonés de nuestros días, que conoce y vive lo que nos enseñan los medievales.

\section{PERSONA, INDIVIDUALIDAD Y SUBSISTENCIA}

Es innegable que el concepto de persona apareció en el ámbito teológico cristiano. La noción filosófica de persona es una de aquellas, que por su origen pueden llamarse cristianas, pero por su contenido son estrictamente filosóficas. Estas nociones son una auténtica aportación directa del cristianismo al pensamiento filosófico. Quizá hubieran permanecido siempre inaccesibles a la razón, si no se hubieran propuesto junto con las verdades de contenido religioso. 
Los grandes escolásticos medievales, siguiendo la tradición de la filosofía cristiana y especialmente el pensamiento de San Agustín y de Boecio, trataron la problemática de la persona, especialmente al ocuparse del misterio de Cristo, el Hombre-Dios. San Anselmo, Alejandro de Hales, San Alberto Magno y San Buenaventura, entre otros, al distinguir la persona de la mera naturaleza insistieron en la propiedades personales, como la unidad, la singularidad, la incomunicabilidad, la dignidad, la substancialidad y la racionalidad.

Sin embargo, el primero que se ocupó propiamente de la fundamentación metafísica de la persona en su entidad y dignidad fue Santo Tomás. Destaca entre todos los autores medievales, por la construcción especulativa de una doctrina sobre la persona, que sintetiza y continúa las anteriores

En su doctrina, se afirma, en primer lugar, que la persona significa lo más individual, lo más propio que es cada hombre, lo más incomunicable, o lo menos común, lo más singular. Una individualidad única, que no se transmite por generación, porque no pertenece a la naturaleza humana genérica, ni a ciertos accidentes suyos, a los que esta predispuesta la misma naturaleza, que es transmitida con ellos de los padres a los hijos.

Lo estrictamente personal no se transmite, porque es propio de cada cual. Indica el Aquinate: «El hombre engendra seres iguales a sí específicamente, pero no numéricamente. Por tanto, las notas que pertenecen a un individuo en cuanto singular, como los actos personales y las cosas que le son propias, no se transmiten de los padres a los hijos. No hay gramático que engendre hijos conocedores de la gramática que el aprendió. En cambio, los elementos que pertenecen a la naturaleza, pasan de los padres a los hijos, a no ser que la naturaleza esté defectuosa. Por ejemplo, el hombre de buena vista no engendra hijos ciegos si no es por defecto especial de la naturaleza. Y si la naturaleza es fuerte, incluso se comunican a los hijos algunos accidentes individuales que pertenecen a la disposición de la naturaleza, como son la velocidad de cuerpo, agudeza de ingenio y otros semejantes. Pero no las cosas puramente personales» ${ }^{1}$.

El término persona no tiene el mismo significado que el de hombre, por expresar esta individualidad. En el lenguaje corriente, el término persona se emplea como equivalente al de hombre. Es una utilización correcta, porque todo hombre es persona. Sin embargo, el nombre persona, por significar esta individualidad, tiene una caracterización lógica y gramatical distinta de hombre y de todas las demás palabras.

$\mathrm{El}$ nombre de persona tiene un significado universal, en cuanto que puede suponerse en muchos sujetos, en los distintos seres personales, y a los que, por ello, puede predicarse a cada uno. En este aspecto coincide con los nombres comunes. Sin embargo, el término persona, a diferencia de estos nombres, no significa una naturaleza universal que se diga de muchos, una esencia objetiva, que se puede predicar de cada uno de ellos, porque lo son, porque realizan esta naturaleza universal en su individualidad.

La palabra «persona» tampoco coincide plenamente con el nombre propio, porque persona, aún significando siempre lo individual o lo distinto, tiene la posibilidad de significar indeterminadamente a todos los individuos personales. En este aspecto es comparable con el nombre común, porque tambiên adquiere esta característica ${ }^{2}$.

La persona posee un estatuto lógico-gramatical único. No sólo porque hay que situarlo entre el nombre común y el nombre propio, sino porque, además de no significar una naturaleza o esencia, como todos los nombres, significa directamente el ser personal propio de cada uno. El término persona, y el significado que expresa, no son como las otras palabras y conceptos. No sólo por el modo que se predican, sino también por su referencia objetiva. L o s nombres se refieren siempre a características esenciales, generales o individuales, que son ex-

1 SANTO TOMÁS, Summa Theologiae, I-II, q. 81, a. 2, in c.

2 Cf. Ibid., I, q. 30, a. 4, in c. 
presadas con más o menos precisión en los diccionarios o enciclopedias. La persona, a diferencia de todos lo demás nombres, sin la mediación de algo esencial, se refiere recta o directamente al ser propio, que es inefable, porque no es de orden esencial.

Sostiene, Santo Tomás, que, en segundo lugar, la persona nombra al ser, al fundamento individual inexpresable de cada hombre, que sólo percibe intelectualmente en su conciencia el propio poseedor y que puede así atribuirlo a los demás y en un grado inferior a las cosas. El Aquinate asumió la definición clásica de persona de Boecio, precisamente por considerar que en ella se denota el ser propio personal. En su obra sobre el misterio de la Encarnación, el filósofo romano define la persona como: «Substancia individual de naturaleza racional» 3 .

También el Aquinate definió la persona, con términos parecidos pero más precisos, del siguiente modo: «Persona es el subsistente distinto en naturaleza racional» ${ }^{4}$. Con estas dos definiciones de persona, quería indicar que: «El ser pertenece a la misma constitución de la persona» ${ }^{5}$. El principio personificador, el que es la raíz y origen de todas las perfecciones de la persona, tanto las generales como las individuales, su individualidad total, es su ser propio.

Todas las perfecciones del ente, que son expresadas por su esencia, se resuelvan en último término en el acto del ser. La persona, sin embargo, sin la mediación de algo esencial, directamente se refiere al ser. Por ello, debe comprenderse como vinculada inmediatamente al ser, y a los trascendentales, que éste principio entitativo básico funda.

La persona guarda una conexión directa y estrecha con los conceptos trascendentales. En este sentido, la persona tiene un carácter «trascendental». Nombra al ser propio, y a los trascendentales, sin designar directamente la naturaleza participante del ser, tal como hacen todos los otros nombres. Menciona inmediatamente al ser, la entidad, la realidad, la unidad, la división o incomunicabilidad, la verdad, la bondad y la belleza, propias del ente personal.

Al igual que por expresar la individualidad, por significar inmediatamente el ser, que en la persona creada es participado, aunque en un grado superior a los otros entes materiales, el término «persona» no es como todos los demás. La persona trasciende todos los géneros y todas las categorías o géneros supremos, puesto que no se explica por determinaciones sobre géneros o especies, ni por ninguna de las categorías, como si fuese algo meramente substancial o accidental.

Lo que hace que un individuo de naturaleza humana, compuesto de cuerpo y alma, sea una persona, no es algo que pertenezca propiamente a esta naturaleza. Es su ser propio, acto primero y fundamental, y que constituye a la misma esencia. El ser propio y proporcionado de cada ente es una realidad metafísica, que no sólo no es captable por los sentidos, como todas las otras, sino que tampoco es objeto de la inteligencia.

El conocimiento es posible, y permite que sepamos que somos personas, porque a cada persona se le revela su ser propio en su conciencia intelectual, en la percepción intelectual de que es o existe. Experiencia que proporciona una absoluta certeza y cuyo objeto, su ser propio, indica como la palabra «yo». Este núcleo interior se distingue de su naturaleza, tanto en su dimensión común como individual o singular, por su carácter permanente y a la vez desconocido, en cuanto su contenido por el mismo sujeto.

El constitutivo formal de la persona, lo que la distingue de la mera naturaleza, es el ser propio y proporcionado a esta esencia. Por este ser personal, la persona subsiste, existe por sí y en sí, de una manera autónoma e independiente. La persona es subsistente y, por tanto, una substancia, tal como se indica en sus definiciones. 


\section{LA PERSONA Y EL ESPÍRITU}

Puede decirse que el ser personal, que designa directamente la persona, es el ser del espíritu. Declara Santo Tomás que: «La persona significa lo más perfecto que hay en toda la naturaleza» ${ }^{6}$. La persona es lo más perfecto y lo más digno. «Es lo más digno de toda la naturaleza ${ }^{7}$. Persona nombra rectamente al máximo nivel de perfección, dignidad, nobleza y perfectividad, en el orden de la realidad creada. De este modo la persona expresa también lo que posee «más» ser, y, por lo mismo, lo más existente, lo más real, lo más individual, lo más diferente, lo más verdadero, lo más bueno y lo más bello. En este sentido, la persona es lo más trascendental de la naturaleza

El grado de ser que posee la persona, y que la constituye formalmente, le confiere unas facultades, la intelectiva y la volitiva, que no se encuentran en los entes no personales, y en las que no interviene intrínsecamente lo,corpóreo. Con respecto a la intelectualidad, afirma Santo Tomás que: «Es imposible que entienda por medio de un órgano corpóreo, porque la naturaleza concreta de tal órgano impediría también el conocimiento de todos los cuerpos (...) Por consiguiente, el principio de intelección llamado mente o entendimiento tiene una operación propia en la cual no participa el cuerpo" ${ }^{8}$.

En los actos de entender y querer, el cuerpo humano, es sólo su condición, porque concurre en ellos de una manera extrínseca e indirecta. «El hecho de que el cuerpo se fatigue por la intelección es algo accidental y se debe a que el entendimiento necesita la cooperación de las fuerzas sensitivas, que son las que le preparan las imágenes»?.

Estas operaciones intelectivas revelan no sólo que en sí mismas son inmateriales, sino también que se explican por la posesión de un ser propio no compartido con la materia, por un ser espiritual, un ser de una substancia inmaterial, de una forma que subsiste, que posee un ser propio, como es el alma humana. Por su misma naturaleza, el alma del hombre necesita unirse al cuerpo, para que su entendimiento pueda recibir los inteligibles a través de los sentidos. Sobre las imágenes, proporcionadas por el conocimiento sensible, y que representan las cosas materiales, actúa su virtud activa, su entendimiento agente, "para hacerlas inteligibles en acto mediante la abstracción» ${ }^{10}$. Por precisar de la sensibilidad, al alma humana le hace falta el cuerpo. El cuerpo lo necesita para saber y el saber para amar. La verdad y el bien así logrados, los necesita para ser feliz.

Por la misma posesión de su ser, las formas subsistentes - tal como ocurre con la de la alma humana, cuyo ser es propio, es independiente del cuerpo, aunque lo necesite para sus operaciones-, están presentes a sí mismas. Poseen de modo consciente el propio ser. De manera que: "Volver a su esencia no significa otra cosa que el subsistir una cosa en sí misma. Pues la forma, en cuanto tiene ser en sí misma, se dice que vuelve sobre sí misma» ${ }^{11}$.

Un espíritu, por poseer un ser propio, sin la materia, es intelectual y volitivo, y también es para sí mismo inteligible y se ama a sí mismo. Formalmente autoconciencia y entender no sólo coinciden entre ellos, y con la inmaterialidad sino que también se identifican con la propia subsistencia. Sostiene, por ello, Santo Tomás que: «Si una arca pudiese subsistir en sí misma, se entendería a sí misma, puesto que la inmunidad de la materia es la razón esencial de la intelectualidad» ${ }^{12}$. La posesión del ser por su forma con independencia de la materia, que

Ibid., I, q. 29, a. 3 , in c.

IDEM., De Potentia, I, q. 9, a. 3, in c.

IDEM, Summa Theologiae, I, q. 75, a. 2, in c.

Ibid., I, q. 75, a. 3, ad 3.

Ibid., I, q. 79, a. 3, ad 2.

Ibid., I, q. 14, a. 2, ad 1.

12 IDEM, De Spiritualibus creaturis, q. un., a. 1, ad 12. 
hace consciente de sí mismo y que permite el conocimiento de la realidad, es lo que constituye al espíritu, a la substancia inmaterial, o a la forma subsistente.

El ser propio, en el grado que lo posee la persona, y que la constituye formalmente, le confiere la autoposesión. La persona se posee no sólo entitativamente, como los demás entes, sino también por sus facultades superiores, que manifiestan, con ello, que son espirituales, o propias de una substancia inmaterial, que posee un ser propio,

En primer lugar, esta posesión personal se realiza por medio de la autoconciencia intelectiva o experiencia existencial de la facultad espiritual inteligible e intelectual, que es el modo como puede conocer el ser. Gracias a ella, aunque en un grado limitado, la persona humana se posee intelectivamente a sí misma.

En segundo lugar, se lleva a cabo la posesión propia de la persona por su facultad espiritual volitiva. Con esta autoposesión, la persona se ama a sí misma, de un modo natural y necesario, pero no, desordenadamente, porque entonces este «amor de sí» se convertiría en egoísmo.

Por ser dueña de sí misma - con sus facultades superiores, aunque en el grado indicado, como corresponde a la limitación de la inteligencia y de la voluntad del ser humano-, la singularidad de la persona es más plena que la de los demás entes substanciales. La individualidad máxima que posee la persona se revela en su especial posesión de su ser.

La persona representa la máxima individualidad. La persona designa siempre lo singular o lo individual, al hombre concreto existente. Las cosas no personales, son estimables por la esencia que poseen. En ellas, todo se ordena, incluida su singularidad, a las propiedades y operaciones específicas de sus naturalezas. De ahí que los individuos solamente interesan en cuanto son portadores de ellas. Todos los de una misma especie son, por ello, intercambiables. No ocurre así con las personas, porque interesan en su misma individualidad, en su personalidad. A diferencia de todos los demás entes singulares, la persona humana es un individuo único, irrepetible e insustituible, con una dignidad, que tiene el carácter de permanencia, actualidad y de idéntico grado

Debe diferenciarse entre la individualidad y la personalidad. Lo material o corporal es el principio de individuación en los seres inertes y animados, y también en el hombre, pero éste último por ser persona posee una individuación mayor. El espíritu humano, en la persona, proporciona una mayor individualidad. Por ella, también se distingue de las otras almas no espirituales. El alma humana, en cuanto es forma del cuerpo, es un principio especificador del hombre. Es este sentido, se comporta igual que las formas sensitivas, vegetativas y de los entes inertes, que hacen que los animales, plantas y entes inanimados pertenezcan una determinada especie, y que, por ella, en su individualidad material posean características comunes específicas, propias de toda la especie a la que pertenecen.

Sin embargo, en cuanto substancia inmaterial, que ya es individual, el alma humana comunica su propia individualidad espiritual al cuerpo, al igual que su ser. A diferencia de las otras almas, el alma de cada hombre es un individuo de la especie alma humana. Es individual por ser un espíritu, una substancia inmaterial subsistente, y que ha sido creada por Dios, subsistente e individual ${ }^{13}$.

La suprema individualidad o singularidad de la persona se expresa con la afirmación de que posee la incomunicabilidad metafísica, de que es lo menos común. En la persona todo esta embebido de incomunicabilidad. En cualquier persona tal singularidad tiene siempre supremacía sobre todo lo específico o genérico. De ahí, que esté incluida formalmente en las dos definiciones de persona examinadas. A la persona, al «subsistente distinto», según la definición de Santo Tomás, o a la «substancia individual», que aparece en la de Boecio, por su totalidad entitativa —que indican los términos «subsistente» $\mathrm{y}$ «substancia»—, y por su singularidad 
-indicada por los de «distinto» e «individual»—, se le puede caracterizar como lo totalmente incomunicable.

El término persona expresa formalmente la incomunicabilidad metafísica. «La forma significada con el nombre de persona no es la naturaleza absolutamente, porque así significaría lo mismo el nombre de hombre y el nombre de persona humana, lo cual es evidente que es falso. Por el nombre de persona se significa formalmente la incomunicabilidad, o la individualidad subsistente, en la naturaleza» ${ }^{14}$.

\section{LA CONCIENCIA PERSONAL}

La autoconciencia propia de la persona explica que tenga también conciencia moral. Se denomina conciencia, en general, al autoconocimiento humano. De modo más específico, la conciencia moral significa el conocimiento de sí de los propios actos en su rectitud o moralidad. Esta conciencia muestra así a su sujeto la bondad o maldad de los mismos. Se puede por ello definir, con Santo Tomás, como un acto de la inteligencia, un juicio o dictamen de la razón práctica en el que se ha aplicado los principios universales del bien a un hecho particular y concreto, que se ha ya realizado o se va a realizar ${ }^{15}$.

Para probar que «la conciencia, propiamente hablando, no es una potencia, sino un acto», el Aquinate da el siguiente argumento: «Conciencia, en la acepción genuina de la palabra, indica la relación de un conocimiento con una cosa, pues conciencia equivale a 'ciencia con otro'. Ahora bien, la aplicación de una ciencia a una cosa se efectúa mediante un acto. Por tanto, está claro, por su mismo concepto nominal, que la conciencia es un acto».

La conciencia es así la conclusión de un razonamiento. La premisa mayor implica el conocimiento de los primeros principios morales evidentes por el hábito innato, llamado sindéresis. La premisa menor, en la que intervine el hábito de la prudencia, que aplica las reglas de la ciencia moral, que incluye desde las conclusiones necesarias que la razón obtiene de los primeros principios hasta las más remotas, al acto singular con sus diversas circunstancias.

El juicio de la conciencia tiene como función propia y primaria la de juzgar el acto que se va a realizar aquí y ahora. Santo Tomás dice que «liga o incita», porque «según nuestra conciencia, juzgamos que una cosa debe o no debe hacerse, y entonces se dice que la conciencia 'incita' o 'liga'».

Una segunda función, secundaria, es la de testificar y juzgar sobre el acto ya realizado. Explica el Aquinate que: «Se dice que testifica (...) cuando reconocemos que hicimos o no hicimos una cosa». Se indica que: «Acusa y remuerde o reprende cuando por la conciencia juzgamos que una cosa ha estado bien o mal hecha, y entonces 'excusa', o bien 'acusa' o 'remuerde'» 16

En los dos dictámenes de la conciencia, llamados de la conciencia antecedente y conciencia consiguiente, porque son antes o después del acto, el primero que tiene el papel de guía, y el segundo de testigo y juez, es esencial la individualidad de la persona. Podría decirse que es una confirmación de su incomunicabilidad.

Como conclusión de un silogismo práctico, la conciencia requiere la individualidad personal. Esta creatividad individual es la que hace que la conciencia pueda ser falsa o errónea. En este error, vencible o invencible, está el origen de los males causado por las propias pasiones ${ }^{17}$.

14 IDEM, De Potentia, q. 9, a. 6, in c.

15 Cf. IDEM, Summa Theologiae, I, q. 17, a. 13, in c.

16 Ibid., I, q. 79, a. 13, in c.

17 Cf. Ibid., I, q. 63, a.1, in c. 
Para comprender esta actividad propia de la conciencia, hay que tener en cuenta, en primer lugar, que, como explica Santo Tomás, la voluntad únicamente desea el bien ${ }^{18}$. En todos los tipos de apetito -natural o sin conocimiento; sensible; e intelectual, como la voluntadse quiere el bien. Sin embargo: «Para que la voluntad tienda a un objeto no se requiere que éste sea bueno en la realidad, sino basta que sea aprehendido como bueno» ${ }^{19}$. La voluntad no puede querer nada que no sea bueno, pero que previamente lo haya conocido como tal. De ahí que sea posible que la voluntad quiera un bien aparente.

El intelectualismo moral de Sócrates se basaba en esta necesidad del conocimiento del bien. La doctrina socrática de la virtud como sabiduría y del vicio como ignorancia, y, su consecuencia, que basta saber para hacer el bien, se apoyaba en esta tesis. Refiriéndose a ella, escribe el Aquinate: «Sócrates (...) concluía que todas las virtudes son ciencia, y todos los pecados ignorancia. Algo decía de verdad, porque, como la voluntad tiende al bien, real o al menos aparente, si eso que no es verdadero bien no se presentase como bueno a la razón, la voluntad no tendería al mal; es decir, no buscaría el mal si no existiera ignorancia o error en la razón».

En segundo lugar, debe tenerse en cuenta también que sobre el proceso discursivo de la conciencia, Santo Tomás siguiendo a Aristóteles, advierte que: «Como para obrar bien el hombre se gobierna por una doble ciencia, universal y particular, basta que falte cualquiera de ellas para que falle la rectitud de la voluntad y de la obra (...) el que está dominado por la pasión no considera en particular lo que en universal ya conoce, porque la pasión impide el considerarlo» ${ }^{20}$. Si las pasiones no están sujetas a la recta razón, dejando intacta la premisa mayor, la más universal, pueden falsear la premisa menor, el juicio particular de la conciencia.

La conclusión mala de la conciencia es posible por esta incorrección en el silogismo. Así, el que una persona: «Elija lo que es malo, como peca, por ejemplo (...) cuando elige el adulterio, que es malo de por sí, estos pecados provienen siempre de algún error o ignorancia, ya que de no tenerlo no se elegiría lo malo como si fuese bueno. El adúltero, ciertamente, yerra en cada caso concreto, eligiendo el deleite de un acto desordenado como si fuese un bien que de momento debe procurarse, movido por la pasión o por el hábito, aunque, en general, no se engañe y piense correctamente en esta materia» ${ }^{21}$. No se equivoca en la premisa más universal, en la premisa mayor, porque sabe que: «Ninguna fornicación debe cometerse».

No obstante, no parece que las premisas, que se utilizan para concluir sean las mismas en la conciencia verdadera que en la conciencia falsa o errónea. El mismo Santo Tomás indica que: «El templado se mueve sólo según el juicio de la razón, por lo que se sirve de un silogismo de tres proposiciones, como el que se deduce del siguiente modo: 'Ninguna fornicación debe cometerse'; 'Es así que este acto es fornicación'; 'luego, este acto no debe hacerse'. En cambio, el intemperante sigue totalmente a la concupiscencia, y por ello se sirve de un silogismo de tres proposiciones como el que deduce así: 'Todo lo placentero debe disfrutarse'; «Es así que este acto es placentero'; 'luego, este acto debe hacerse'».

Sin embargo, existe una coincidencia entre los dos razonamientos de las conciencias, porque en ambos hay una premisa implícita, que no aparece de modo inmediato en ellos. En la conciencia falsa relacionada con la pasión, y con la virtud de la continencia, que la regula, en la conciencia verdadera. De manera que: «Tanto el continente como el incontinente se mueven de dos modos: según la razón, ciertamente para evitar el pecado, pero según la concupiscencia para cometerlo; pero en el continente vence el juicio de la razón, más en el incontinente vence el movimiento de la concupiscencia. Por lo que ambos se sirven de un silogismo de cuatro proposiciones, pero para llegar a conclusiones contrarias». 
En la conciencia del virtuoso actúa esta premisa mayor: «'Ningún pecado debe cometerse'. Y esto lo propone según un juicio de razón: pero versa según un movimiento de la concupiscencia, tratándose del corazón de aquel para quien todo lo placentero debe seguirse; pero debido a que en ello vence el juicio de la razón, asume y concluye bajo el primero: 'Esto es pecado', 'luego no debe hacerse'».

Con esta premisa oculta, que es más universal, que la primera premisa mayor, el razonamiento de dos silogismos encadenados de la conciencia, podría formularse así: Ningún pecado debe cometerse; Ninguna fornicación debe cometerse; Esto es una fornicación; Luego, no debe hacerse.

También, en la conciencia de la persona que se deja dominar por la pasión, actúa otra premisa latente. «El incontinente, en quien vence el movimiento de la concupiscencia, asume y concluye bajo lo segundo: 'Esto es placentero', 'luego, debe hacerse'; y tal es propiamente el que peca por debilidad. Y por esto es patente que aunque conozca de modo universal, con todo no conoce de modo universal; pues no lo asume según la razón, sino según la concupiscencia» ${ }^{22}$. La verdad que conoce y que está por ello como premisa, aunque no es que la lleva, en este caso, a la conclusión, es que «ninguna fornicación debe cometerse».

Las cuatro proposiciones de esta conciencia falsa, serían, por consiguiente: Todo lo placentero debe hacerse; Ninguna fornicación debe cometerse; Este acto es placentero; Luego, este acto debe hacerse

En esta conciencia, la premisa mayor, «todo lo placentero debe hacerse», desde la que se concluye, no es más universal, que «ninguna fornicación debe cometerse». Propiamente no es universal, porque no es de evidencia mediata ni inmediata. Se admite únicamente por interés de la concupiscencia o del deseo desordenado. La deducción, por tanto, no lo es verdaderamente, por tomar como premisa mayor, una proposición particular y la segunda premisa, que si es universal, no actúa. Si se le da la forma de un juicio general, es para poder concluir, ya que de dos premisas particulares no se concluye nada.

Por consiguiente, las dos deducciones coinciden en una premisa, «ninguna fornicación debe cometerse», y además en ambas colocada como segunda premisa. Sin embargo, la conciencia falsa puede concluir lo contrario de la verdadera, es decir, que tiene que hacerse, porque se la toma como premisa menor. En cambio, en la conciencia verdadera se la considera como una segunda premisa mayor. Como explica Santo Tomás: «Quien tiene la ciencia en universal se siente impedido por la pasión para hacer su aplicạción y sacar las conclusiones, y acude a otro principio universal que la misma pasión le sugiere; y mediante ella concluye. Por eso dijo el Filósofo que el silogismo del incontinente tiene cuatro proposiciones: dos universales, una de razón - por ejemplo, que 'ninguna fornicación se puede cometer'-, otra de la pasión -por ejemplo, que 'la delectación hay que seguirla'-. La pasión impide que la razón siga y concluya a base de la primera, $\mathrm{y}$, dominándola, le hace tomar y seguir la segunda» ${ }^{23}$.

En definitiva, el pseudorazonamiento de la conciencia falsa implica un conocimiento universal de la virtud, un saber ético, y sin embargo, contra la doctrina socrática, no concluye en el bien. La primera proposición, «todo lo placentero debe hacerse», a la que se le da una forma universal, fundada en la pasión, y que fue desconocida por Sócrates, es la que lleva a la justificación errónea de la bondad del acto malo.

La conciencia implica individualidad por ser un acto de la razón, un juicio del entendimiento práctico, del entendimiento en cuanto se aplica a una conducta concreta de una determinada persona. Una actividad que podría llamarse creativa, en cuanto fruto de una individualidad personal. Sin embargo, es esencial advertir que la verdad y su fuerza obligatoria no las concede misma conciencia. 
La obligatoriedad de la conciencia, como norma individual de los actos buenos, no implica que sea el árbitro único, porque depende de una norma universal, la ley moral y de ella recibe su carácter obligatorio. Por tanto, los juicios morales de la conciencia individual o la conciencia publica no son verdaderos o adecuados a la realidad por el hecho de que sean de la conciencia, de que sean fruto de una conciencia recta, o que se correspondan con el dictamen de la propia conciencia, de una conciencia, en este sentido, auténtica. No basta que la conciencia sea recta para obligar. Es preciso que la conciencia sea verdadera, que dictamine según la ley moral. No es la conciencia la que determina la premisa mayor, lo que está bien y lo que está mal. Ni tampoco la premisa menor, en cada momento determinado, establece la bondad o maldad de los actos concretos. La obligación se obedecer a la conciencia no funda una ética individualista ni subjetivista. La obligatoriedad de toda norma moral procede de la ley.

El juicio de la conciencia no anula el carácter universal de la ley y de la obligación, ni supone rebelarse a su autoridad, sino que lo confirma y acata. El deber que formula la conciencia se apoya en el deber anterior expresado por la ley natural. La conciencia depende de esta norma objetiva, que fundamenta el imperativo de sus decisiones racionales. La existencia de la conciencia revela, por ello, la de la ley natural, que, por su origen, es ley divina. Al buscar la verdad y al juzgar con su conciencia según la verdad descubierta en la ley natural, la misma conciencia se convierte en verdadera. Es una auténtica conciencia. Con ello, el hombre vive en la verdad y es un hombre verdadero.

Eudaldo Forment Facultad de Filosofía Universidad de Barcelona Baldiri i Reixac, s/n 08028 Barcelona 